Yuan-Jian YANG

Weiwen PENG

Shun-Peng ZHU

Hong-Zhong HUANG

\title{
A BAYESIAN APPROACH FOR SEALING FAILURE ANALYSIS CONSIDERING THE NON-COMPETING RELATIONSHIP OF MULTIPLE DEGRADATION PROCESSES
}

\section{ZASTOSOWANIE METODY BAYESA DO ANALIZY USZKODZEŃ USZCZELNIEŃ Z UWZGLĘDNIENIEM WSPÓŁWYSTĘPUJĄCYCH PROCESÓW DEGRADACJI O CHARAKTERZE NIEKONKURUJĄCYM}

\begin{abstract}
Degradation analysis is an effective method for reliability analysis when failure time data is rare or hard to observe. Multiple degradation analysis with competing risk model is often used to implement the degradation analysis. However, in reality, the failure of a system is often a result of a combination of multiple degradation processes, such as the sum of multiple degradations. To handle this non-competing relationship of multiple degradation processes, this paper presents a new reliability model for multiple degradation processes analysis. The proposed model is demonstrated through a case-study of a spool valve. In this paper, the gamma process is adopted to construct the reliability model. The Bayesian method is used to obtain the estimations of model parameters and reliability indexes by taking account of uncertainty. The results can then be further used as valuable information for further degradation analysis and decision-making considering uncertainty.
\end{abstract}

Keywords: Bayesian method, reliability analysis, degradation process, sealing

\begin{abstract}
Analiza degradacji jest skuteczna metoda analizy niezawodnościowej w przypadkach gdy dane sa skape lub trudne do zaobserwowania. W badaniach często wykorzystuje się analizę wspótwystępujących degradacji z zastosowaniem modelu zagrożeń konkurujących. Jednak $w$ rzeczywistości, awaria systemu często jest wynikiem wystapienia degradacji niekonkurujacych, t.j. wynikiem sumy lub kombinacji wspótwystępujących procesów degradacji. Aby uwzględnić tę relacje między niekonkurującymi procesami degradacji, $w$ artykule przedstawiono nowy model niezawodności służący do analizy współwystępujących procesów degradacji. Proponowany model zilustrowano za pomoca studium przypadku rozdzielnika suwakowego. Przedstawiony w pracy model niezawodności skonstruowano w oparciu o proces gamma. Do oszacowania parametrów modelu oraz indeksów niezawodności zastosowano metodę Bayesa z uwzględnieniem niepewności. Uzyskane wyniki można wykorzystać w przyszłości jako cenne dane do dalszej analizy degradacji i podejmowania decyzji z uwzględnieniem niepewności.
\end{abstract}

Stowa kluczowe: metoda Bayesa, analiza niezawodności, proces degradacji, uszczelnienie.

\section{Introduction}

Degradation is generally considered as one type of damage to a device. It accumulates over time or task, and finally results in a failure once the accumulated damage reaches a predefined threshold. Degradation models have been widely used in reliability engineering, and have been well reviewed recently by Gorjian [6] and Elsayed [3]. In reality, the degradation of a system may consist of multiple degradation processes. There are some studies [15, 20-22] focusing on the multiple degradation processes, and they are all based on the competing model of multiple degradation processes. In competing model, the system fails when any of the multiple degradation processes reaches its corresponding failure threshold. However, it may not be suitable for some mechanical devices, because the relationship of different degradation processes is not always competing. According to this issue, this paper presents a modified multiple degradation model to describe some degradation processes which are common in mechanical systems. A spool valve is taken as the object of this study to investigate the non-competing relationship of degradation processes. Spool valves are basic parts in hydraulic systems, and their reliability performance has a direct impact on the reliability of the entire hydraulic system. In spool valves, the spool slides in and out of position within the sleeve, alternately blocking and opening the fluid intake and outtake ports. The high frequency and numerous sliding operations results in the wearing of spool and sleeve, making the sealing deteriorated, and eventually leading to the sealing failure. The leakage, usually caused by the wear degradation of spools and sleeves, is the main failure mode of this device, and has been investigated by many studies $[2,4,5,19]$. However, the detailed analysis of this wear degradation process has not been well studied. A further investigation of the failure mechanism and reliability assessment of 
sealing are carried out in this paper. A modified multiple degradation process model is introduced and the detailed analysis is implemented using Bayesian method. Normally, Bayesian method is flexible for incorporating various types of information to improve the reliability estimation and analysis. To achieve this point, multiple sources of information should be available. However, in this study, there is no other information available other than the degradation observations. This paper attempts to highlight another significant aspect of Bayesian method. It is the ability for incorporating the uncertainty within the estimation results, which are normally given as posterior distributions of model parameters. These posterior distributions are of critical importance for further analysis of newly-observed data, which can be further used as the prior information for the Bayesian analysis of these newly-observed data. These posteriors are also critical for the optimal decision-making for the system operation and management, for which uncertainty should be incorporated. Because the degradation observations are the only available information for this research, noninformative prior distribution based Bayesian method is used. This is due to the fact that uniform distribution is a simple distribution that can express no prior information in Bayesian calculation. It is also can facilitate the Markov chain Monte Carlo simulation for the calculation of posterior distribution. For more information about derivation of non-informative priors, please refer to the works by O'Hagan and Forster [13]. Based on these considerations, the Bayesian method is used to aggregate quantitative prior information for further degradation analysis and for uncertainty-related decision making.

The remaining segments of this paper are organized as follows. Section 2 introduces the structure and working principle of a spool valve, and analyses the root causes of failure and mechanisms of the sealing. In Section 3, a multiple degradation model with no competing relationship is established based on the gamma process. Section 4 uses an example to illustrate the proposed model and parameter estimation. Section 5 presents the conclusion of this paper and discusses the future work.

\section{The sealing failure analysis of a spool valve}

When a spool valve is used to control the flow directions of the oil of a hydraulic system, this spool valve is called a directional valve. A 3 -position directional valve, with two working positions and one normal position, is taken as an example to illustrate the working principle of such type of spool valve. A spool valve consists of a cylindrical spool and a sleeve. When the spool slides towards right forming the normal position, as shown in left of Fig. 1, the hydraulic oil flows through the valve from port $\mathrm{P}$ to port $\mathrm{B}$, and form port $\mathrm{A}$ to port $\mathrm{T}$. On the contrary, when the spool slides towards left forming the normal position, the hydraulic oil flows through the valve from port $\mathrm{P}$ to port $\mathrm{A}$, and form port $\mathrm{B}$ to port $\mathrm{T}$. When the spool is in the normal position, all ports are closed. In this study, the movement of a spool moving from the normal position to the right or left position and then return to the normal position is called one stroke.

As shown in Fig 1, the clearance is formed between the spool and the sleeve. The quantity of internal leakage fluid passing through

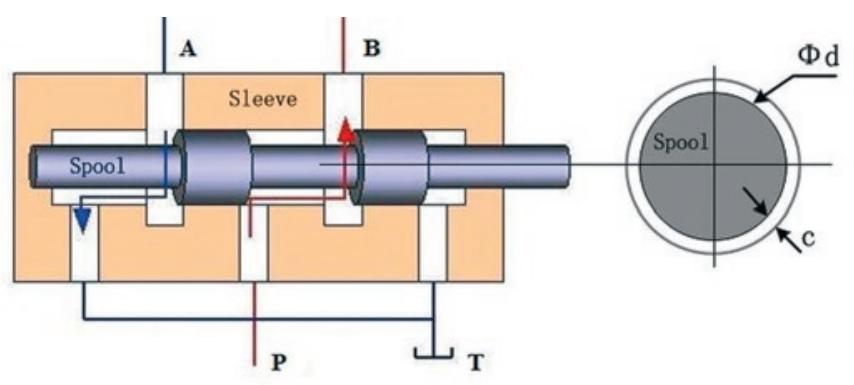

an assembled valve, of which the spool is in the normal position, is called null leakage. The null leakage is controlled in a certain range. The upper limit of this range depends on the valve sealing class and the valve size, which is given by some standards, such as the ANSI/ FCI 70-2-2006, GB/T 17213.4-2005, and IEC 60534-4-2006 3.0. The flow in the narrow circular clearance of a spool valve can be viewed as laminar, and is governed by the following equation [7, 10],

$$
Q=\Delta P \frac{\pi d c^{3}}{12 \mu L}
$$

where $Q$ denotes the flow of leakage due to the clearance. $\Delta P$ is the pressure difference between both sides of the clearance, $\pi$ is the circumference ratio, $d$ denotes the valve spool diameter, $c$ is the radial clearance height, $L$ is the clearance length, and $\mu$ is the dynamic viscosity of hydraulic oil.

The movement of the spool restricts or permits the flow, thus it controls the amount of oil flow. At the same time, the high frequency back-and-forth movements of sliding cause the wear of spools and sleeves. It finally causes the increase of clearance and null leakage. The degradation of sealing of a spool valve can be represented by the increasing value of clearance, which is due to the wear degradation of the spool and sleeve. When the null leakage increases to the maximum level, the sealing of the spool valve is failed. When the maximum allowable null leakage is determined by the corresponding standard, the maximum allowable clearance can be estimated approximately by Eq. (1) or calculated precisely by CFD (Computational Fluid Dynamics) Methods $[8,17]$.

\section{The multiple degradation models}

The Wiener process and Gamma process are common stochastic processes for modelling degradation processes. The increments of the Wiener process may be negative, but always positive for the Gamma process. For mechanical devices, degradations, such as wear, erosion, fatigue, is always irreversible. Hence there is a nonnegative characteristic of the degradation values. In this paper, the Gamma process, which involves independent nonnegative increments, is adopted to characterize the wear-out degradation of the spool valve.

A non-negative valued process $\{X(t), t>0\}$ is considered. $X(t)$ represents the measured degradation for an individual unit at time $t$. A gamma process has the following properties [18]:

- $X(0)=0$;

- The increments $\Delta X(t)$ are independent;

- $\Delta X(t)$ follows a gamma distribution $G a(\Delta \alpha(t), \lambda)$, where $\alpha(t)$ is a given monotone increasing function with $\alpha(0)=0$, and the probability density function (PDF ) $g(x)$ is defined by:

$$
g(x \mid \alpha(t), \lambda)=\frac{\lambda^{\alpha(t)}}{\Gamma(\alpha(t))} x^{\alpha(t)-1} e^{-\lambda x}
$$

A system is considered failed when the degradation value reach the threshold, the cumulative distribution function of the time-to-failure can be written as:

$$
F(t)=\operatorname{Pr}\{X(t) \geq C\}=\int_{x=C}^{\infty} g(x) d x=\frac{\Gamma(\alpha(t), C \lambda)}{\Gamma(\alpha(t))}
$$

Fig. 1. Schema of a spool valve and clearance 
where $\Gamma(a, b)=\int_{z=b}^{\infty} z^{a-1} e^{-z} d z$ is the upper incomplete gamma function with $a>0$ and $b \geq 0$.

The reliability of a system at time $t$ can be calculated by:

$$
R(t)=1-F(t)
$$

In reality, a product may consist of multiple degrading components or a component may have multiple degradation processes. In such case, it is necessary to use the multiple degradation processes models. Zhao and Elsayed [23] investigated a reliability modelling method with both catastrophic and degradation failures under accelerated stress conditions. Wang and Coit [20] presented a general modelling framework for multiple degradation measures. Pan and Balakrishna [15] introduced a reliability estimation method for a system with bivariate degradations that involve two or more performance characteristics. Wang and Pham [22] developed a model of the dependent competing risks with multiple degradation processes and random shock using time-varying copulas. In all these studies, the multiple degradations processes are treated as mutually competing. In fact, the relationship is not always competing in certain mechanical devices. This section firstly presents the competing model with multiple degradation processes according to the previous studies [15, $20,22,23]$.

In the competing model with multiple degradation processes, assuming that $\mathrm{m}$ is the number of the degradation processes, $D_{i}(t)$ is the degradation measure of the $i^{\text {th }}$ degradation process at time $t, C_{i}$ is the failure threshold of the $i^{\text {th }}$ degradation process. A component or a system is considered as failed, when any of its degradation processes reaches the corresponding failure threshold. The component or system reliability at time $t$ can be written as:

$$
R(t)=\operatorname{Pr}\left\{D_{1}(t)<C_{1}, D_{2}(t)<C_{2}, \ldots, D_{i}(t)<C_{i}\right\}, i=1, \ldots, m
$$

As discussed above, each degradation process may reach a corresponding failure threshold at different time. For some mechanical devices, different degradation processes may lead to one failure, and Eq. (5) may not be able to capture the relationship between the reliability and the multiple degradation processes.

More generally, a system with $m$ degradation processes, which lead to one failure mode, $C$ is the failure threshold, the reliability at time $t$ can be defined as:

$$
R(t)=\operatorname{Pr}\left\{D_{1}(t)+D_{2}(t)+\ldots+D_{i}(t)<C\right\}, i=1, \ldots, m
$$

At the same time, if $X_{i}$ follows a Gamma distribution with shape parameter $k_{i}$ and scale parameter $\theta$ for $i=1,2, \ldots, N$, the following relationship can be obtained as:

$$
\sum_{i=1}^{N} X_{i} \sim \operatorname{Gamma}\left(\sum_{i=1}^{N} k_{i}, \theta\right)
$$

Based on the properties of gamma process, Eq. (6) and Eq. (7), a new general setting of multiple degradation processes model is obtained, which is applicable when the relationship is not competing. A system with $m$ degradation processes leading to one failure mode together, and the $i^{\text {th }}$ degradation process follow the gamma process with the parameter $k_{i} \Delta t$ and $\theta$ for $i=1,2, \ldots, m$, where $C$ is the failure threshold. According to Eq. (3), Eq. (4) and Eq. (6) the reliability of the system at time $t$ can be expressed as,

$$
R(t)=1-\frac{\Gamma\left(\sum_{i=1}^{m} k_{i} t, C \theta\right)}{\Gamma\left(\sum_{i=1}^{m} k_{i} t\right)}
$$

\section{Illustrative example and Parameter estimation}

As discussed in Section 2, the radial clearance height is the crucial factor for the reliability of sealing. When the total wear of spool and sleeve is bigger than the maximum allowable clearance height, the null leakage increases to the maximum level, and the sealing of the spool valve is failed. When the clearance between the spool and the sleeve reaches the maximum allowable value, the sealing fails. The increased clearance is caused by the wear degradation of the spool and the sleeve. $D_{s p}(n)$ is the wear volume of a spool after $n$ strokes, with $D_{s p}(n)=0 . \quad D_{s l}(n)$ is the wear volume of a sleeve after $n$ strokes, with $D_{s l}(n)=0 . D_{M}$ is the maxima allowable wear value that represents the failure threshold of the sealing, which can be calculated by subtracting the initial fit clearance from the maximum allowable clearance value. The initial fit clearance is a basic parameter for a spool valve. The calculation of the maximum allowable clearance is presented in Section 2. After $n$ strokes, the reliability of a spool valve sealing can be estimated by:

$$
R_{s}(n)=\operatorname{Pr}\left(D_{s p}(n)+D_{s l}(n)<D_{M}\right)
$$

Assuming that the wear of a spool occurs randomly in every stroke and it can be described by a gamma process $D_{s p}(n)$ with $\Delta D_{s p}(n) \sim G a\left(\alpha_{1} \Delta n, \lambda\right)$, where $\Delta D_{s p}(n)=D_{s p}(n+\Delta n)-D_{s p}(n)$ , and $G a\left(\alpha_{1} \Delta n, \lambda\right)$ is a gamma distribution with a shape parameter $\alpha_{1} \Delta n$ and a scale parameter $\lambda$. In this paper, the wear degradation of a sleeve is described by another gamma process $D_{s l}(n)$ with $\Delta D_{s l}(n) \sim G a\left(\alpha_{2} \Delta n, \lambda\right)$, where $\Delta D_{s l}(n)=D_{s l}(n+\Delta n)-D_{s l}(n)$, and $G a\left(\alpha_{2} \Delta n, \lambda\right)$ is a gamma distribution with a shape parameter $\alpha_{2} \Delta n$ and a scale parameter $\lambda$, which is the same as $D_{s p}(n)$.

Therefore, we have $\Delta D_{s p}(n)+\Delta D_{s l}(n) \sim G a\left(\left(\alpha_{1}+\alpha_{2}\right) \Delta n, \lambda\right)$. According the properties of the gamma process, $\left\{D_{s p}(n)+D_{s l}(n)\right\}$ can be described by a new gamma process. In addition, $\Delta\left(D_{s p}(n)+D_{s l}(n)\right)=\Delta D_{s p}(n)+\Delta D_{s l}(n) \sim G a\left(\left(\alpha_{1}+\alpha_{2}\right) \Delta n, \lambda\right)$

According to Eq. (8), the reliability of a spool valve sealing can be obtained as follows:

$$
R_{S}(n)=1-\frac{\Gamma\left(\alpha_{1} n+\alpha_{2} n, D_{m} \lambda\right)}{\Gamma\left(\alpha_{1} n+\alpha_{2} n\right)}
$$

Note that the reliability evaluation of sealing is the probability as shown in Eq. (6). The proposed model and parameter estimation is illustrated in this section.

In this paper, simulated data, as shown in Table 1, are generated to demonstrate the applicability of the proposed multiple degradation models and parameter estimation. The number of samples is six, and the wear volumes are observed per 50,000 strokes. The threshold is set to 120 . Then, the wear degradation path of spool valves can be depicted in Fig. 2. 
Table 1 Simulated wear volumes of spool valves (unit: micron)

\begin{tabular}{|c|c|c|c|c|c|c|c|c|c|c|c|c|c|c|c|c|c|c|c|c|c|}
\hline \multirow{2}{*}{\multicolumn{2}{|c|}{ Unit }} & \multicolumn{20}{|c|}{ Number of strokes (10 thousands) } \\
\hline & & 5 & 10 & 15 & 20 & 25 & 30 & 35 & 40 & 45 & 50 & 55 & 60 & 65 & 70 & 75 & 80 & 85 & 90 & 95 & `100 \\
\hline \multirow{2}{*}{$\begin{array}{c}\text { Sample } \\
1\end{array}$} & spool & 7 & 9 & 19 & 22 & 28 & 34 & 37 & 39 & 45 & 46 & 50 & 54 & 58 & 64 & 69 & 74 & 76 & 81 & 83 & 86 \\
\hline & sleeve & 4 & 6 & 8 & 13 & 14 & 18 & 19 & 21 & 22 & 24 & 27 & 30 & 32 & 34 & 37 & 39 & 46 & 49 & 52 & 55 \\
\hline \multirow{2}{*}{$\begin{array}{c}\text { Sample } \\
2\end{array}$} & spool & 6 & 9 & 13 & 16 & 17 & 20 & 24 & 27 & 30 & 35 & 38 & 39 & 43 & 48 & 51 & 53 & 58 & 60 & 66 & 68 \\
\hline & sleeve & 3 & 4 & 12 & 12 & 14 & 15 & 17 & 18 & 19 & 21 & 23 & 24 & 26 & 28 & 30 & 32 & 34 & 36 & 38 & 45 \\
\hline \multirow{2}{*}{$\begin{array}{c}\text { Sample } \\
3\end{array}$} & spool & 4 & 8 & 12 & 16 & 20 & 25 & 28 & 31 & 35 & 37 & 41 & 44 & 47 & 50 & 56 & 59 & 63 & 65 & 66 & 70 \\
\hline & sleeve & 1 & 2 & 5 & 8 & 10 & 14 & 16 & 20 & 23 & 26 & 27 & 32 & 33 & 35 & 37 & 40 & 41 & 43 & 47 & 49 \\
\hline \multirow{2}{*}{$\begin{array}{c}\text { Sample } \\
4\end{array}$} & spool & 1 & 5 & 9 & 13 & 15 & 17 & 21 & 25 & 28 & 32 & 34 & 37 & 41 & 41 & 45 & 49 & 54 & 55 & 60 & 63 \\
\hline & sleeve & 5 & 7 & 9 & 10 & 11 & 13 & 17 & 18 & 21 & 25 & 29 & 33 & 33 & 36 & 39 & 43 & 45 & 46 & 47 & 50 \\
\hline \multirow{2}{*}{$\begin{array}{c}\text { Sample } \\
5\end{array}$} & spool & 2 & 4 & 0 & 9 & 12 & 17 & 19 & 22 & 25 & 29 & 32 & 34 & 37 & 46 & 48 & 50 & 52 & 54 & 57 & 60 \\
\hline & sleeve & 1 & 2 & 9 & 11 & 13 & 16 & 22 & 24 & 29 & 31 & 32 & 35 & 35 & 37 & 41 & 43 & 44 & 46 & 47 & 51 \\
\hline \multirow{2}{*}{$\begin{array}{c}\text { Sample } \\
6\end{array}$} & spool & 6 & 8 & 11 & 13 & 18 & 24 & 29 & 30 & 35 & 37 & 40 & 42 & 44 & 47 & 48 & 53 & 58 & 60 & 63 & 68 \\
\hline & sleeve & 4 & 7 & 8 & 11 & 16 & 19 & 20 & 24 & 26 & 28 & 30 & 32 & 33 & 35 & 36 & 38 & 41 & 43 & 45 & 47 \\
\hline
\end{tabular}

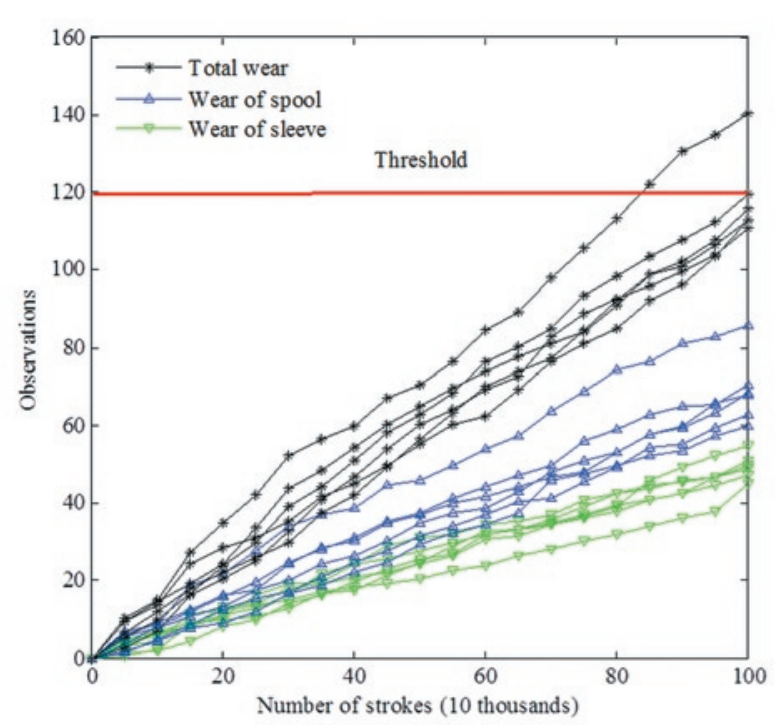

Fig. 2. Wear degradation paths of spools

Let $D_{s p}\left(n_{i j}\right)$ with $j=1,2, \ldots, 20$ and $i=1,2, \ldots, 6$ be the $j$ th spool wear observation of sample $i$. Let $d_{i j}=D_{s p}\left(n_{i j}\right)-D_{s p}\left(n_{i, j-1}\right)$ , be the wear increment of unit $i$. Following the degradation model introduced above, the wear increments $d_{i j}$ obtained from the simulated data are independent and follow a gamma distribution $G a\left(\alpha_{1} \Delta n_{i j}, \lambda\right)$ with $\Delta n_{i j}=n_{i j}-n_{i, j-1}$. At the same time, let $D_{s l}\left(n_{i j}\right)$ with $j=1,2, \ldots, 20$ and $i=1,2, \ldots, 6$ be the $j$ th sleeve wear observation of sample $i$. Let $d_{i j}^{\prime}=D_{s l}\left(n_{i j}\right)-D_{s l}\left(n_{i, j-1}\right)$ denote the wear increment of unit $i$, and $d_{i j}^{\prime}$ follow another gamma distribution $G a\left(\alpha_{2} \Delta n_{i j}, \lambda\right)$ with $\Delta n_{i j}=n_{i j}-n_{i, j-1}$. When the wear observations of the valves are obtained as $D$ with $\boldsymbol{v}=\left(\alpha_{1}, \alpha_{2}, \lambda\right)$ being the parameter vector, the information contained in this simulated data is presented as the likelihood function,

$$
L\left(D, v \mid \alpha_{1}, \alpha_{2}, \lambda\right)=\prod_{i=1}^{6} \prod_{j=2}^{20} g\left(\Delta d_{i j} \mid \alpha_{1}, \lambda\right) g\left(\Delta d_{i j}^{\prime} \mid \alpha_{2}, \lambda\right)
$$

where $g(\bullet)$ is the probability density function of a gamma distribution as shown in Eq. (2), $g\left(\Delta d_{i j} \mid \alpha_{1} \Delta n_{i j}, \lambda\right)$ stands for the probability that the observed value is $\Delta d_{i j}$, where the parameter vector is $\left(\alpha_{1} \Delta n_{i j}, \lambda\right)$,

$$
\begin{aligned}
L\left(D, v \mid \alpha_{1}, \alpha_{2}, \lambda\right) & =\prod_{i=1}^{6} \prod_{j=2}^{20} g\left(\Delta d_{i j} \mid \alpha_{1}, \lambda\right) g\left(\Delta d_{i j}^{\prime} \mid \alpha_{2}, \lambda\right) \\
& =\prod_{i=1}^{6} \prod_{j=2}^{20} \frac{\lambda^{\alpha_{1} \Delta n_{i j}} \Gamma\left(\alpha_{1} \Delta n_{i j}\right)}{\Delta d_{i j} \alpha_{1} \Delta n_{i j}-1} e^{-\lambda \Delta d_{i j}} \frac{\lambda^{\alpha_{2} \Delta n_{i j}}}{\Gamma\left(\alpha_{2} \Delta n_{i j}\right)} \Delta d_{i j}^{\prime \alpha_{2} \Delta n_{i j}-1} e^{-\lambda \Delta d_{i j i j}^{\prime}}
\end{aligned}
$$

Suppose prior information for the wear of the spool valves can be obtained and quantified as joint prior distribution for the model parameters as $\pi(\theta)=\pi\left(\alpha_{1}, \alpha_{2}, \lambda\right)$. Bayesian method has widely been used in reliability research $[9,11,14,16,24]$. More details about Bayesian theory can be referred to O'Hagan et al. [1, 11, 12]. Following the Bayesian theory, the joint posterior distribution of model parameters is obtained as:

$$
\begin{aligned}
p\left(\alpha_{1}, \alpha_{2}, \lambda, v\right) & \propto \pi(\theta) L(D, v \mid \theta)=\pi\left(\alpha_{1}, \alpha_{2}, \lambda\right) L\left(D, v \mid \alpha_{1}, \alpha_{2}, \lambda\right) \\
& =\pi\left(\alpha_{1}, \alpha_{2}, \lambda\right) \prod_{i=1}^{6} \prod_{j=2}^{20} \frac{\lambda^{\alpha_{1} \Delta n_{i j}}}{\Gamma\left(\alpha_{1} \Delta n_{i j}\right)} \Delta d_{i j}^{\alpha_{1} \Delta n_{i j}-1} e^{-\lambda \Delta d_{i j}} \frac{\lambda^{\alpha_{2} \Delta n_{i j}}}{\Gamma\left(\alpha_{2} \Delta n_{i j}\right)} \Delta d_{i j}^{\prime \alpha_{2} \Delta n_{i j}-1} e^{-\lambda \Delta d_{i j i j}^{\prime}}
\end{aligned}
$$

where $p\left(\alpha_{1}, \alpha_{2}, \lambda, v\right)$ is the joint posterior distribution for model parameters. It is a description of the combination of prior information and the information contained in the observed degradation data. The reliability assessment of the valve spool sealing after $n$ strokes, is calculated based on the joint posterior distribution of model parameters as:

$$
R_{S}(n \mid D)=\int_{\alpha_{1}, \alpha_{2}, \lambda>0} p\left(\alpha_{1}, \alpha_{2}, \lambda \mid D\right) \frac{\Gamma\left(\alpha_{1} n+\alpha_{2} n, D_{m} \lambda\right)}{\Gamma\left(\alpha_{1} n+\alpha_{2} n\right)} \mathrm{d} \alpha_{1} \mathrm{~d} \alpha_{2} \mathrm{~d} \lambda
$$


Based on the historical data, prior distributions for these parameters are given as:

$$
\alpha_{1} \sim \mathrm{U}(0,100), \alpha_{2} \sim \mathrm{U}(0,100), \lambda \sim \mathrm{U}(0,100)
$$

These posterior distributions are kernel distributions of posterior samples generated using MCMC simulation. By obtaining these posterior distributions, information conveyed by degradation observations presented in Table 1 are quantified and translated into probability

where $\mathrm{U}(0,100)$ is the uniform distribution with

an interval of $(0,100)$. In this paper, these noninformative priors are given in the form of uniform distributions with relevant large intervals. A uniform distribution with large interval is sufficient to be chosen as a non-informative prior.

The MCMC method is used to generate posterior samples of model parameters. The WinBUGS is adopted to facilitate the imple-
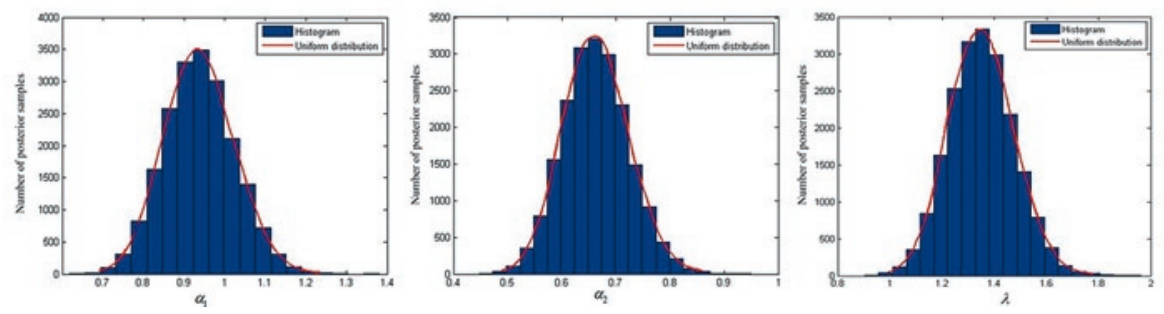
mentation of MCMC for the Bayesian degradation analysis of the wear degradation data. 20,000 posterior samples are generated using WinBUGS with 10,000 samples for burn-in. Estimations of model parameters are presented in Table 2.

Table 2. Estimations of model parameters

\begin{tabular}{||c|c|c|c|c||}
\hline \multirow{2}{*}{} & \multirow{2}{*}{ Mean } & \multirow{2}{*}{$\begin{array}{c}\text { Standard } \\
\text { Deviation }\end{array}$} & \multicolumn{2}{|c|}{ Confidence interval } \\
\cline { 4 - 5 } & & & $2.5 \%$ & $97.5 \%$ \\
\hline$\alpha_{1}$ & 0.938 & 0.08679 & 0.7745 & 1.113 \\
\hline$\alpha_{2}$ & 0.663 & 0.06116 & 0.5477 & 0.7878 \\
\hline$\lambda$ & 1.351 & 0.1258 & 1.113 & 1.606 \\
\hline
\end{tabular}

Fig. 3. Posterior distributions of model parameters

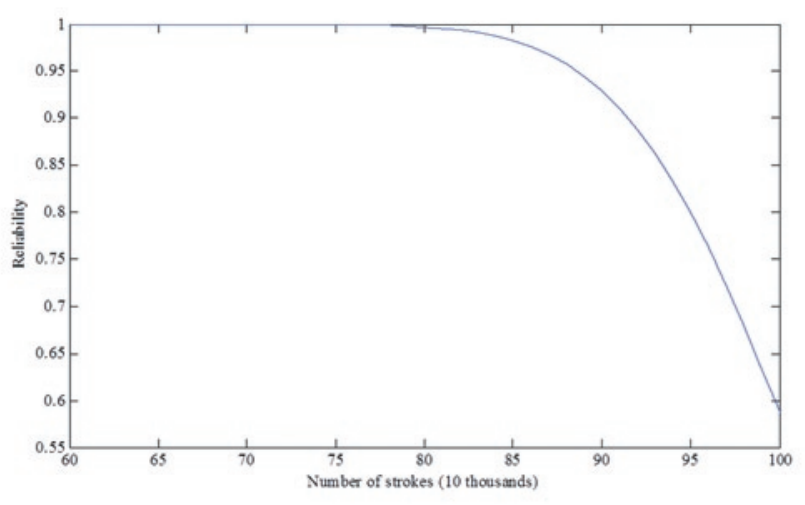

Fig. 4. Reliability of the spool valve sealing

The estimation results presented in Table 2 are summarized from the generated posterior samples. Posterior distributions of model parameters $\alpha_{1}, \alpha_{2}$ and $\lambda$ are shown in Fig. 3. The mean of $\alpha_{1}$ is 0.938 with a standard deviation 0.08679 , the mean of $\alpha_{2}$ is 0.663 with a standard deviation 0.06116 , and the mean of $\lambda$ is 1.351 with a standard deviation 0.1258 . The estimation confidence intervals of these parameters are obtained as $[0.7745,1.113]$ for $\alpha_{1},[0.5477,0,7878]$ for $\alpha_{2}$, and $[1.113,1.606]$ for $\lambda$.

As discussed above, the wear of a spool is described by a gamma process $\left\{D_{s p}(n) ; n \geq 0\right\}$, of which the shape parameter is a function of $n$ (times of operation), written as $0.938 n$, the scale parameter is 1.351. For the other gamma process $\left\{D_{s l}(n) ; n \geq 0\right\}$ used to describe the wear degradation of a sleeve, the shape parameter is $0.663 n$, and the scale parameter is 1.351 . Based the estimations of parameters presented above, we have $\Delta\left(D_{s p}(n)+D_{s l}(n)\right) \sim G a\left(\left(\alpha_{1}+\alpha_{2}\right) \Delta n, \lambda\right)=G a(1.601 \Delta n, 1.351)$. As discussed in Section 3, according to the new gamma process, the shape parameter is a function of time (times of operation) $1.601 \Delta n$, and the scale parameter is 1.351 . It describes the wear degradation of a spool valve and quantify the change of clearance height between the sleeve and the spool of a valve. When the failure threshold is set as 120 , the reliability of the spool valve sealing can be obtained using Eq. (9), as presented in Fig. 4. The reliability assessment of sealing is close to engineering experience. It indicates that the proposed multiple degradation processes model and parameter estimation method are applicable for this case study of spool valves. distributions of model parameters. These distributions can be further used for reliability analysis of similar valves based on newly observed degradation observations, which can be implemented through the proposed degradation model and Bayesian method in this paper.

\section{Conclusion and future work}

This paper presents a new multiple degradation model based gamma process to characterize the reliability of spool valve sealing subject to multiple degradation processes. The reliability analysis of sealing is investigated based on the valve structure and its working principle. The joint wear degradation of the spool and sleeve lead to the sealing failure. The maximum allowable clearance is used to indicate the failure threshold of sealing, and its calculation method is also presented in this paper. Moreover, a non-competing multi-degradation processes model is proposed based on the sealing failure analysis of a spool valve. This model is suitable for the situation where multiple degradation processes lead to one failure mode, which is quite common for mechanic devices. A numerical example is further provided to verify the model and illustrate the proposed method.

As future efforts, this paper leaves some open questions. First, the dependence of the multiple degradation processes is not considered. Second, the assumption that the wear degradation process of spool and sleeve has the same scale parameter can be eliminated. Third, the reliability data, which are used to illustrate the model, are simulated, and it is desirable to test the model in real-world cases. These are the interesting topics that deserve further investigation.

\section{Acknowledgement}

The Fundamental Research Funds for the Central Universities under the contract number ZYGX2010J094, the National Natural Science Foundation of China under the contract number 11272082. 


\section{References}

1. Bernardo JM, Smith AF. Bayesian theory vol. 405: John Wiley \& Sons, 2009

2. Ellman A. Leakage behaviour of four-way servovalve. Proceedings of ASME International Mechanical Engineering Congress and Exposition 1998; 163-167.

3. Elsayed EA. Overview of reliability testing. IEEE Transactions on Reliability 2012; 61(2): 282-291, http://dx.doi.org/10.1109/ TR.2012.2194190.

4. Eryilmaz B, Wilson BH. Combining leakage and orifice flows in a hydraulic servovalve model. Journal of dynamic systems, measurement, and control 2000; 122(3): 576-579, http://dx.doi.org/10.1115/1.1286335.

5. Gordić D, Babić M, Milovanović D, Savić S. Spool valve leakage behaviour. Archives of Civil and Mechanical Engineering 2011; 11(4): 859-866, http://dx.doi.org/10.1016/S1644-9665(12)60082-X.

6. Gorjian N, Ma L, Mittinty M, Yarlagadda P, Sun Y. A review on degradation models in reliability analysis. London: Springer, 2010, http:// dx.doi.org/10.1007/978-0-85729-320-6_42.

7. Han SS, Liu X, Chao Z, Meng A. Evaluation Model Study of Hydraulic Components Leakage for In Situ Testing. Machine tool \& Hydraulics 2009; 37(3): 119-121.

8. Jiang J, Guo Y, Zeng Lc, Zhan CC, Fu SG. Simulation and Analysis of Leakage for Clearance Seal of Hydraulic Cylinder. Lubrication Engineering 2013; 38(7): 75-79.

9. Li YF, Mi J, Huang HZ, Xiao NC, Zhu SP. System reliability modeling and assessment for solar array drive assembly based on Bayesian networks. Eksploatacja i Niezawodnosc - Maintenance and Reliability 2013; 15: 117-122.

10. Li Y. Research to the Wear and Geometric Error Relations of Electro hydraulic Servo Valve. Procedia Engineering 2011; 15: 891-896, http:// dx.doi.org/10.1016/j.proeng.2011.08.165.

11. Mi J, Li YF, Huang HZ, Liu Y, Zhang X. Reliability analysis of multi-state systems with common cause failure based on Bayesian Networks. Proceedings of International Conference on Quality, Reliability, Risk, Maintenance, and Safety Engineering 2012; 1117-1121, http://dx.doi. org/10.1109/icqr2mse.2012.6246417.

12. O'Hagan A, Buck CE, Daneshkhah A, Eiser JR, Garthwaite PH, Jenkinson DJ, Oakley JE, Rakow T. Uncertain judgements: eliciting experts' probabilities. John Wiley \& Sons, 2006, http://dx.doi.org/10.1002/0470033312.

13. O'Hagan A, Forster JJ. Kendall's advanced theory of statistics, volume 2B: Bayesian inference vol. 2: Arnold, 2004.

14. Pan R. A Bayes approach to reliability prediction utilizing data from accelerated life tests and field failure observations. Quality and Reliability Engineering International 2009; 25(2): 229-240, http://dx.doi.org/10.1002/qre.964.

15. Pan Z, Balakrishnan N. Reliability modeling of degradation of products with multiple performance characteristics based on gamma processes. Reliability Engineering \& System Safety 2011; 96(8): 949-957, http://dx.doi.org/10.1016/j.ress.2011.03.014.

16. Peng W, Huang HZ, Xie M, Yang Y, Liu Y. A Bayesian Approach for System Reliability Analysis With Multilevel Pass-Fail, Lifetime and Degradation Data Sets. IEEE Transactions on Reliability 2013; 63(3): 689-699, http://dx.doi.org/10.1109/TR.2013.2270424.

17. Tallman J, Lakshminarayana B. Numerical simulation of tip leakage flows in axial flow turbines, with emphasis on flow physics: Part I: Effect of tip clearance height. Journal of turbomachinery 2001; 123(2): 314-323, http://dx.doi.org/10.1115/1.1368881.

18. Van Noortwijk J. A survey of the application of gamma processes in maintenance. Reliability Engineering \& System Safety 2009; 94(1): 2-21, http://dx.doi.org/10.1016/j.ress.2007.03.019.

19. Vaughan N, Pomeroy P, Tilley D. The contribution of erosive wear to the performance degradation of sliding spool servovalves. Proceedings of the Institution of Mechanical Engineers, Part J: Journal of Engineering Tribology 1998; 212(6): 437-451, http://dx.doi. org/10.1243/1350650981542245.

20. Wang P, Coit DW. Reliability prediction based on degradation modeling for systems with multiple degradation measures. Proceedings of The Annual Reliability and Maintainability Symposium 2004; 302-307, http://dx.doi.org/10.1109/rams.2004.1285465.

21. Wang Y, Pham H. Dependent competing-risk degradation systems. London: Springer, 2011, http://dx.doi.org/10.1007/978-0-85729-470-8_7.

22. Wang Y, Pham H. Modeling the dependent competing risks with multiple degradation processes and random shock using time-varying copulas. IEEE Transactions on Reliability 2012; 61(1): 13-22, http://dx.doi.org/10.1109/TR.2011.2170253.

23. Zhao W, Elsayed E. An accelerated life testing model involving performance degradation. Proceedings of The Annual Reliability and Maintainability Symposium 2004; 324-329.

24. Zhu SP, Huang HZ, Smith R, Ontiveros V, He LP, Modarres M. Bayesian framework for probabilistic low cycle fatigue life prediction and uncertainty modeling of aircraft turbine disk alloys. Probabilistic Engineering Mechanics 2013; 34: 114-122, http://dx.doi.org/10.1016/j. probengmech.2013.08.004.

\section{Yuan-Jian YANG \\ Weiwen PENG \\ Shun-Peng ZHU \\ Hong-Zhong HUANG}

Institute of Reliability Engineering

University of Electronic Science and Technology of China

No. 2006, Xiyuan Avenue, West Hi-Tech Zone

Chengdu, Sichuan, 611731, P. R. China

E-mail: hzhuang@uestc.edu.cn, yuanjyang@hotmail.com, zspeng2007@uestc.edu.cn, weiwenpeng@hotmail.com 